\title{
The impact of high-frequency current variability on dispersion off the eastern Antarctic Peninsula
}

\author{
A. Trasviña, ${ }^{1}$ Karen J. Heywood, ${ }^{2}$ A. H. H. Renner, ${ }^{2,3,4}$ S. E. Thorpe, ${ }^{3}$ A. F. Thompson,,${ }^{5,6}$ \\ and L. Zamudio ${ }^{7}$ \\ Received 28 January 2011; revised 17 August 2011; accepted 19 August 2011; published 17 November 2011.
}

[1] We present observations of high-frequency current variability on the continental shelf and the slope of the Antarctic Peninsula using Lagrangian surface drifters deployed as part of the Antarctic Drifter Experiment: Links to Isobaths and Ecosystems (ADELIE) project. Here we focus on high-frequency processes such as tides and inertial oscillations that are typically smoothed out of large-scale spatially averaged, and/or temporally averaged, observed current fields. We investigate the role that this class of motion plays in the transport of physical or biogeochemical properties. Lateral displacements on the shelf and slope are found to be larger than displacements in deeper waters where tidal currents are negligible. We apply this result in a parameterization of the lateral dispersion during an off-line drifter modeling study. The outcome is an improvement on the modeling of Lagrangian drifting particles compared with a standard random walk scheme.

Citation: Trasviña, A., K. J. Heywood, A. H. H. Renner, S. E. Thorpe, A. F. Thompson, and L. Zamudio (2011), The impact of high-frequency current variability on dispersion off the eastern Antarctic Peninsula, J. Geophys. Res., 116, C11024, doi:10.1029/2011JC007003.

\section{Introduction}

[2] Physical processes by which water masses, nutrients, trace metals and plankton cross the boundary between continental shelves and the deep ocean are much discussed, but little understood. A working group established by the Scientific Committee on Oceanic Research (SCOR) and the International Association for the Physical Sciences of the Oceans (IAPSO) recently discussed [Johnson, 2011] the mechanisms that facilitate this exchange (Deep Ocean Exchange with the Shelf, DOES). This paper is a contribution to this discussion. Here, we focus on high-frequency processes such as tides and inertial oscillations that are typically smoothed out of the large-scale spatially averaged, or temporally averaged, observed currents. We investigate the variability of this class of motion across the shelf break using observations gathered during the Antarctic Drifter

\footnotetext{
${ }^{1}$ Departamento de Oceanografía Física-Unidad La Paz, Centro de Investigación Cientifica y de Educación Superior de Ensenada, La Paz, Mexico.

${ }^{2}$ School of Environmental Sciences, University of East Anglia, Norwich, UK.

${ }^{3}$ British Antarctic Survey, Natural Environment Research Council, Cambridge, UK.

${ }^{4}$ Now at Norwegian Polar Institute, Tromsø, Norway.

${ }^{5}$ Department of Applied Mathematics and Theoretical Physics, Centre for Mathematical Sciences, University of Cambridge, Cambridge, UK.

${ }^{6}$ Now at Division of Geological and Planetary Sciences, California Institute of Technology, Pasadena, California, USA.

${ }^{7}$ Center for Ocean and Atmospheric Prediction Studies, Florida State University, Tallahassee, Florida, USA.
}

Copyright 2011 by the American Geophysical Union. 0148-0227/11/2011JC007003
Experiment: Links to Isobaths and Ecosystems (ADELIE) [Thompson and Heywood, 2008].

[3] The continental shelf of the Antarctic Peninsula is of particular interest because it is a likely source of the dissolved iron required to feed the phytoplankton bloom downstream of the peninsula [Martin et al., 1990; Fitzwater et al., 2000]. The Southern Ocean is typically iron-limited and is characterized by low chlorophyll concentrations, outside of large blooms found downstream of certain shelf regions. The Antarctic Peninsula is also a spawning ground for the Antarctic krill Euphausia superba [Marr, 1962]. A wealth of studies has simulated the pathways that these krill may take toward the sub-Antarctic island of South Georgia where they form the basis of a thriving ecosystem of higher predators (reviewed by Murphy et al. [2007]). Particle-tracking techniques are used in numerical models, typically applying long-term mean velocity fields (several days, weeks, monthly or even annual mean). The high-frequency (short time scale) processes responsible for cross-frontal exchange are not resolved in these velocity fields. To replace these, random walk techniques are added to simulate the effects of small (time and space) scale processes such as eddies, inertial oscillations and tides. Here we consider whether we can use observed measurements of drifter dispersion at the tip of the Antarctic Peninsula to improve upon the assumption of a purely random walk. We focus on the high-frequency variability of the currents because of its possible contribution to the diffusive and cross-shelf transport processes in this area.

[4] Several processes induce variability in the circulation around the Antarctic Peninsula region (Figure 1). The cyclonic (clockwise) Weddell Gyre follows the coastline and topographic slope and is influenced by both wind and 


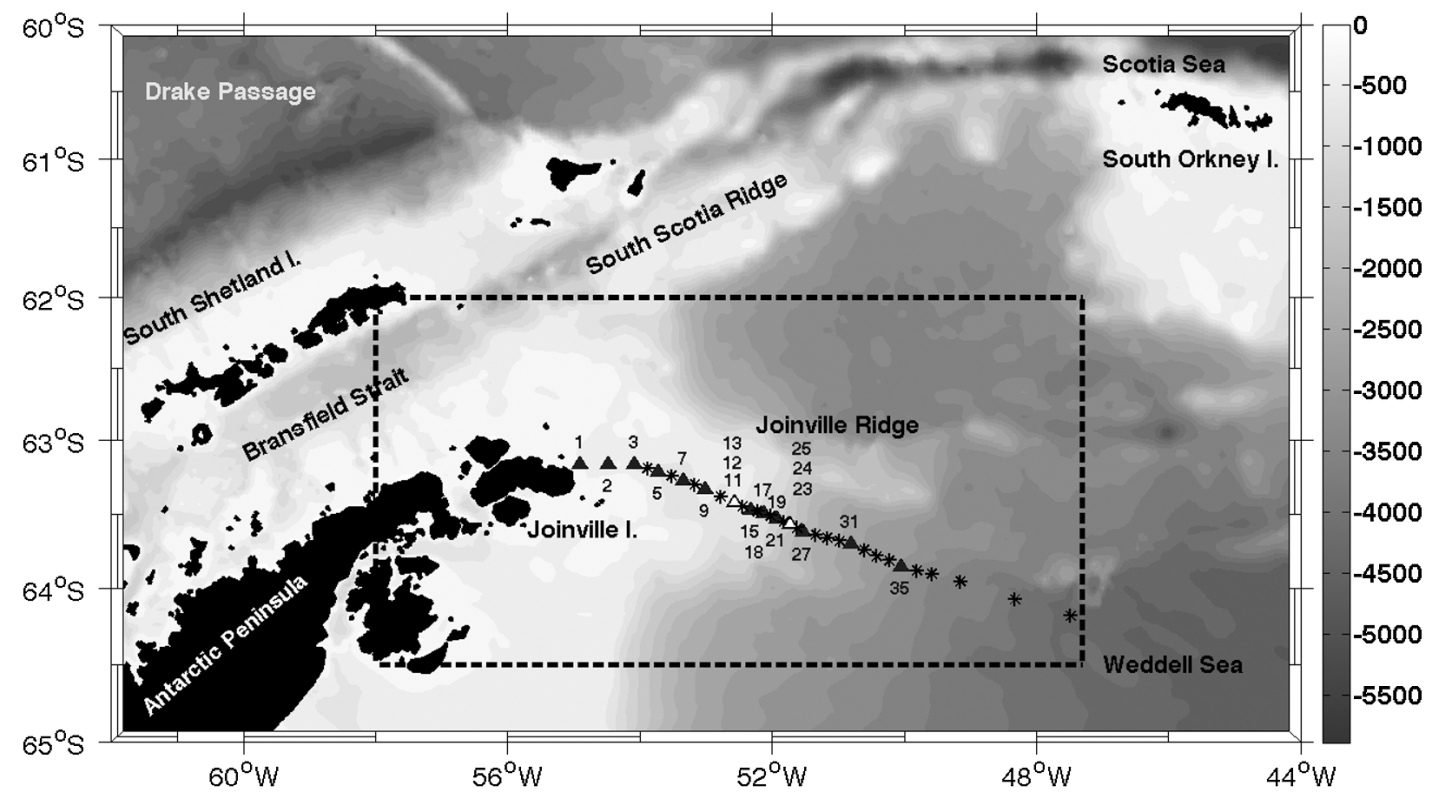

Figure 1. Drifter deployment during ADELIE shown superimposed on the bathymetry from ETOPO2. Triangles/stars mark SVP-G/SVP drifter deployment sites. Clusters of 3 SVP-G drifters were deployed simultaneously at the two sites marked with open triangles. Sequential deployment numbers are included for SVP-G drifters. The area delimited by dashed lines is expanded in Figure 3.

thermohaline forcing [Fahrbach and Beckmann, 2001]. Thompson and Heywood [2008] documented two frontal features in the northwestern Weddell Sea observed during the ADELIE hydrographic section period. At the shelf break, the Antarctic Slope Front is characterized by a $\mathrm{V}$-shaped depression in both isotherms and isohalines. This narrow front has a typical width of $50 \mathrm{~km}$ and associated current speeds between 0.1 and $0.3 \mathrm{~m} \mathrm{~s}^{-1}$. Further offshore, a second deep-reaching feature is identified as the Weddell Front.

[5] Sudden wind accelerations produce an inertial response in the upper-ocean currents. The local inertial period at the Antarctic Peninsula is short, varying between 13.7 and $13.3 \mathrm{~h}$ (at latitudes of $61^{\circ} \mathrm{S}$ and $64^{\circ} \mathrm{S}$, respectively), and the internal Rossby radius is small, about 5 to $10 \mathrm{~km}$ [Beckmann et al., 1999]. From the Rossby adjustment problem [Gill, 1982], geostrophic balance is expected to occur for flows with typical lengths of the order of the Rossby radius. In the Weddell Sea a periodic disturbance of the pressure gradient will attain geostrophic balance if it lasts more than about $13 \mathrm{~h}$ (the inertial period) and if it occurs along a length scale of 5 to $10 \mathrm{~km}$ (the Rossby radius). Structures of this size are difficult to detect by typical (coarse grid) hydrographic surveys or to simulate by numerical models that, usually, have grid spacing larger than the Rossby radius.

[6] In addition, periodic processes with diurnal or higher frequency, including tidal components and coastal wind systems, become subinertial forcing agents in middle and high latitudes. Poleward of the critical latitude $\left(30^{\circ} \mathrm{N} /{ }^{\circ} \mathrm{S}\right)$ such processes can interact with inertial motion. One example is the resonant enhancement of the inertial currents described by Simpson et al. [2002] at the critical latitude. In the higher latitudes of the Weddell Sea, Robertson [2005] reported enhancement of inertial oscillations by the semidiurnal tide.

[7] This work reports Lagrangian observations of highfrequency currents off the tip of the Antarctic Peninsula. The paper is organized as follows. Section 2 describes the drifters, data, and numerical methods. In section 3 we discuss the Lagrangian and spectral properties of the observed flow. Section 4 applies the observed displacement properties of the drifters to a numerical simulation of particle dispersal at the Antarctic Peninsula and compares the resultant particle tracks with those from a model with an untuned random walk. In section 5 we discuss and summarize our findings.

\section{Data and Spectral Methods}

[8] The Antarctic Drifter Experiment: Links to Isobaths and Ecosystems (ADELIE) experiment was carried out on the RRS James Clark Ross (cruise JR158) between $61^{\circ} \mathrm{S}$ and $64^{\circ} \mathrm{S}$ to the east of the Antarctic Peninsula (Figure 1) from 6 to 19 February 2007. This is in the austral summer when the sea ice cover in the Weddell Sea reaches its seasonal minimum. One goal was to study the influence of the bathymetry in controlling the splitting and steering of frontal jets [Thompson et al., 2009]. Forty Clearsat II surface drifters were deployed on 8 February 2007 eastward from the tip of the peninsula roughly along the Joinville Ridge as shown in Figure 1. All drifters were drogued at a $15 \mathrm{~m}$ depth and relayed data through the Argos satellite system. Half of these transmitted Global Positioning System (GPS) positions using the Argos System (SVP-G). The rest were the typical Argos Lagrangian drifters (SVP) used by the Global Drifter Program and kindly contributed to the experiment by Peter Niiler (Scripps Institution of Oceanography, San 
Diego, California). Drifters with GPS were deployed over the shelf and the shelf break (marked with triangles in Figure 1). Two clusters with three drifters each (open triangles in Figure 1) were deployed over the continental slope in order to track the currents associated with the Antarctic Slope Front. Drifters 6, 23, 27, and 32 are not included because their tracks are too short to obtain the low-pass record. This discussion will focus on the high-frequency variability contained in approximately 18 days of detailed observations obtained from 36 Lagrangian drifters (Figure 3). This period includes the maximum available simultaneous drifter observations near and around the coastal regions, equivalent to about 650 drifter days or more than 31,000 half-hourly fixes.

[9] Traditional SVP drifters use the Argos system to produce one position fix approximately every hour, at the latitudes of this experiment. SVP-G drifters produce one fix every $30 \mathrm{~min}$. Argos fixes possess higher uncertainty $(350 \mathrm{~m})$ in their positions than GPS fixes $(30 \mathrm{~m})$ [Thompson et al., 2009]. For the purpose of this experiment however, both SVP and GPS drifter tracks (and their derived velocities) will be discussed. This is because they exhibit similar rotary spectra in the range of the high-frequency motion addressed in this paper. The periodicity of the motion of interest $(>12 \mathrm{~h})$ is significantly larger than the sampling rates. The spatial scale considered $\left(>10^{4} \mathrm{~m}\right)$ is also larger than the uncertainty of either type of drifter. We obtained raw position data from the $\mathrm{ftp}$ site of the Data Acquisition Center of the Atlantic Oceanographic and Meteorological Laboratory (NOAA), Miami, Florida (AOML). A procedure that follows the work by Hansen and Poulain [1996] was then applied to the raw data to eliminate obvious errors and outliers and to obtain a "clean" half-hourly record for each drifter. This is the same data set described by Thompson et al. [2009], but they used the six-hourly data subset and removed the high-frequency variability to focus on the topographic influences.

[10] The PL64 low-pass filter described by Beardsley et al. [1985] and used by Thompson et al. [2009] was applied to produce smoothed drifter tracks. These are then subtracted from the original drifter data set to separate highfrequency from low-frequency variations. This filter was originally designed to filter $\mathrm{K}_{1}, \mathrm{M}_{2}$, and higher tidal frequency components from oceanographic time series. It has a half-power period of $33 \mathrm{~h}$ and is designed for hourly time series. Drifter records were subsampled to this sampling rate to apply the filter, in order to obtain the low-pass (filtered) records.

[11] Lagrangian drifter statistics are based on the following formulation, as derived by Davis [1991]. Lagrangian positions are described by a horizontal position vector $\mathbf{r}$ defined by Lagrangian components:

$$
\mathbf{r}=\left[x\left(t \mid x_{0}, t_{0}\right), y\left(t \mid x_{0}, t_{0}\right)\right] .
$$

[12] The position vector $\mathbf{r}$ is a function of time $(t)$ and of each drifter's deployment position at time $t_{0}\left(x_{0}\right)$. In this notation a vertical bar is used to separate the label, following Davis [1991]. The Lagrangian mean of $\mathbf{r}$ is defined as a running mean, or a filter applied over consecutive subsets of positions $(t+\tau)$, as the mean vector $(\mathbf{R})$ :

$$
\mathbf{R}\left(t \mid x_{0}, t_{0}\right)=\left\langle\left(x\left(t \mid x_{0}, t_{0}\right), y\left(t \mid x_{0}, t_{0}\right)\right)\right\rangle
$$

where \langle\rangle indicates the filter applied over the $(t+\tau)$ times and $\mid x_{0}, t_{0}$ serves to indicate that the operation is applied to each individual trajectory (drifter), as noted before. Consequently the mean vector $\mathbf{R}$ is equivalent to the path of the mean currents described by Thompson et al. [2009]. Here we are concerned with the small space-scale and time-scale processes that modulate the mean flow. These are described by the residual displacements, $\mathbf{r}^{\prime}$, that can be derived for each component of the position vector, and for each drifter, as:

$$
\mathbf{r}^{\prime}\left(t \mid x_{0}, t_{0}\right)=\mathbf{r}\left(t \mid x_{0}, t_{0}\right)-\mathbf{R}\left(t \mid x_{0}, t_{0}\right)
$$

[13] The residual velocities can be obtained from the time derivative of (3), as:

$$
\mathbf{v}^{\prime}\left(t \mid x_{0}, t_{0}\right)=\partial \mathbf{r}^{\prime}\left(t \mid x_{0}, t_{0}\right) / \partial t .
$$

[14] Figure 2 illustrates the result of the processing procedure. Figure $2 \mathrm{a}$ shows the time series of velocity components $(\mathrm{U}, \mathrm{V})$ obtained from one drifter trajectory after despiking and interpolation. Figure $2 \mathrm{~b}$ shows the velocity after applying filter PL64 to the raw data (termed the Lagrangian mean). The Lagrangian residual velocities (Figure 2c) result from subtracting the filtered data from the original data, and reveal the high-frequency phenomena that are the topic of this paper. Figure $2 \mathrm{~d}$ compares the original drifter trajectory with the filtered trajectory (shown here for a short-time segment corresponding to the thick mean line in Figure 2b).

[15] Rotary spectra are obtained from the time series of the 36 drifters. Each time series contains 850 data points, sampled every $30 \mathrm{~min}$, making nearly 18 days of simultaneous data (17.7 days). Time series are partitioned into $n$ continuous segments of equal length [Emery and Thompson, 2004] and the mean spectrum is calculated from the spectra of these $n$ realizations. This yields a spectrum that is smooth and best represents the dominant frequencies in the record. With the chosen record length $T=425 \mathrm{~h}$, sampling rate $(\Delta T=$ $0.5 \mathrm{~h})$, and number of partitions $(n=3)$ the spectral estimates presented here are bounded by the Nyquist frequency $\left(1 / 2 \Delta T=1 \mathrm{~h}^{-1}\right)$ and the partition length $(n / T)=0.007 \mathrm{~h}^{-1}$, corresponding to 1 and $142 \mathrm{~h}$ periods, respectively.

[16] For tidal predictions we use the Antarctic Peninsula version 04.01 barotropic tidal model. This is a high-resolution model $\left(1 / 30^{\circ} \times 1 / 60^{\circ}\right.$, approximately $\left.2 \mathrm{~km}\right)$ for the domain from $76^{\circ} \mathrm{S}$ to $58^{\circ} \mathrm{S}$ and from $120^{\circ} \mathrm{W}$ to $30^{\circ} \mathrm{W}$, following the methodology described by Padman et al. [2002]. We made predictions using the Tide Model Driver (TMD) Matlab toolbox from Earth \& Space Research (ESR; http:// www.esr.org/). This toolbox provides access to modeled grids of tidal harmonic constituents, and allows predictions of barotropic sea surface height and velocity at specified locations and times.

[17] Model results from the Hybrid Coordinate Ocean Model (HYCOM) are used to run the off-line Lagrangian numerical experiments discussed in section 4 [Bleck, 2002]. The grid used in this study is an eddy-resolving $\left(1 / 12^{\circ}\right.$ equatorial resolution) Mercator projection from $78.64^{\circ} \mathrm{S}$ to $47^{\circ} \mathrm{N}$. The model is forced with three-hourly winds and daily averaged heat fluxes from the Fleet Numerical Meteorology and Oceanography Center's Navy Operational Global 

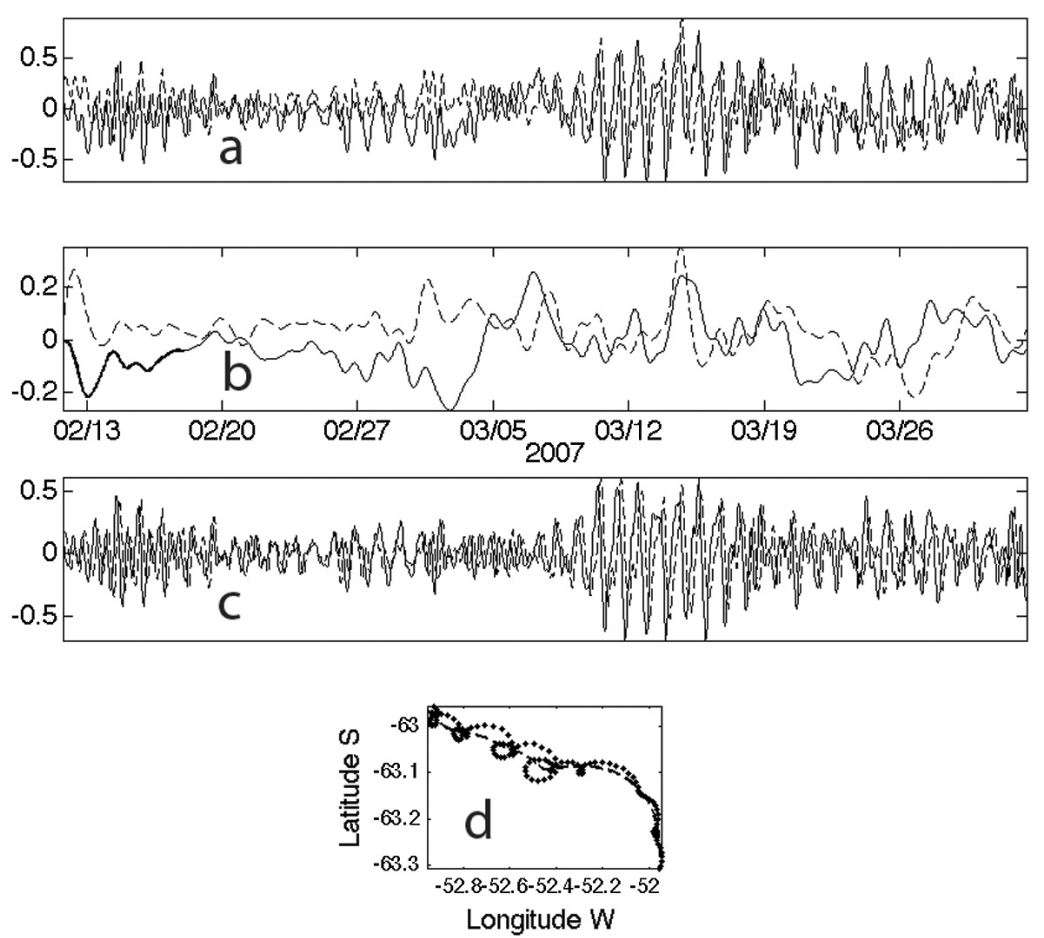

Figure 2. Example of velocities estimated from one SVP-G drifter (Slope drifter No. 19): (a) raw velocity components U (solid) and V (broken line); (b) mean velocity components, estimated after applying filter PL64 to the raw positions; (c) residual velocities resulting from subtracting the mean from the raw data; and (d) section of the trajectory (identified by the thick line on Figure 2b) showing raw (dotted line) and mean (broken line) positions.

Atmospheric Prediction System (NOGAPS) [Rosmond et al., 2002]. It includes realistic bottom topography and coastline geometry based on a modified version of the $1 / 30^{\circ} \mathrm{NRL}$ DBDB2 topography (available at http://www7320.nrlssc. navy.mil/DBDB2_WWW). The model output used here includes the months of January to April 2007.

\section{Results and Discussion: Spectral Properties and Lagrangian Displacement}

[18] Figure 3 illustrates the trajectories for the 18 days when data are available for all 36 drifters. The mean surface flow is steered by the bathymetric features at the tip of the Antarctic Peninsula, as discussed by Thompson et al. [2009]. Drifter excursions from their deployment sites increase within two frontal jets, the Antarctic Slope Front on the slope and the Weddell Front further offshore, as identified by Thompson and Heywood [2008]. The focus here is on the high-frequency motion revealed by the corkscrew paths shown here superimposed on the mean trajectories. We group the trajectories based on the depth range they span during the period to explore the depth dependency of the flow. This classification is slightly different to that presented by Thompson et al. [2009] because their discussion is focused on the mean flow. In Figure 3, drifters in black stay in the shallow waters of the continental shelf (0-200 $\mathrm{m}$ isobaths) whereas the mid-gray drifters move along the continental slope (200-1000 $\mathrm{m}$ isobaths), and the light gray drifters spend most of their time in deep waters (isobaths $>1000 \mathrm{~m}$ ).
[19] The description of the Lagrangian properties of these groups is based on the residual trajectory plots of Figure 4. These are the trajectories without their Lagrangian mean (as in equation 3). The most striking feature is the difference in size of the radial distribution of residuals or "displacement" of those drifters on the shelf and the continental slope (subsequently grouped as shallow drifters) compared to those on deep water. The displacement of deepwater drifters almost always falls within $2 \mathrm{~km}$. In contrast, the largest radii are found on the shelf and continental slope. Displacement of shallow drifters, except drifters 2 and 3, lie up to $3-5 \mathrm{~km}$ from their Lagrangian means. Drifters 2 and 3 remain inside an eddy-like circulation during the whole period (further discussed in section 5). Consistent with a linear superposition of flow components, the magnitude of Lagrangian residuals (Figure 4) appears decoupled from that of the mean flow. The strong advection within either of the frontal jets does not exert any obvious influence on the displacement radii.

[20] Such displacement is attributed here to the combined effect of tidal and wind-induced inertial currents. Barotropic tidal currents from the AntPen tidal model (Figure 5) are represented in Figure 5 as tidal ellipses in the $\mathrm{K}_{1}$ (diurnal) and $\mathrm{M}_{2}$ (semidiurnal) constituents. Ellipses with a semimajor axis less than $5 \mathrm{~cm} \mathrm{~s}^{-1}$ are disregarded and not drawn. Tidal currents are large only in the shallow domain of the continental shelf and slope. They are larger and more unidirectional (as shown by elongated ellipses) in regions where the flow is constricted by the bathymetry. The rotational sense of the currents during one period is, in general, 


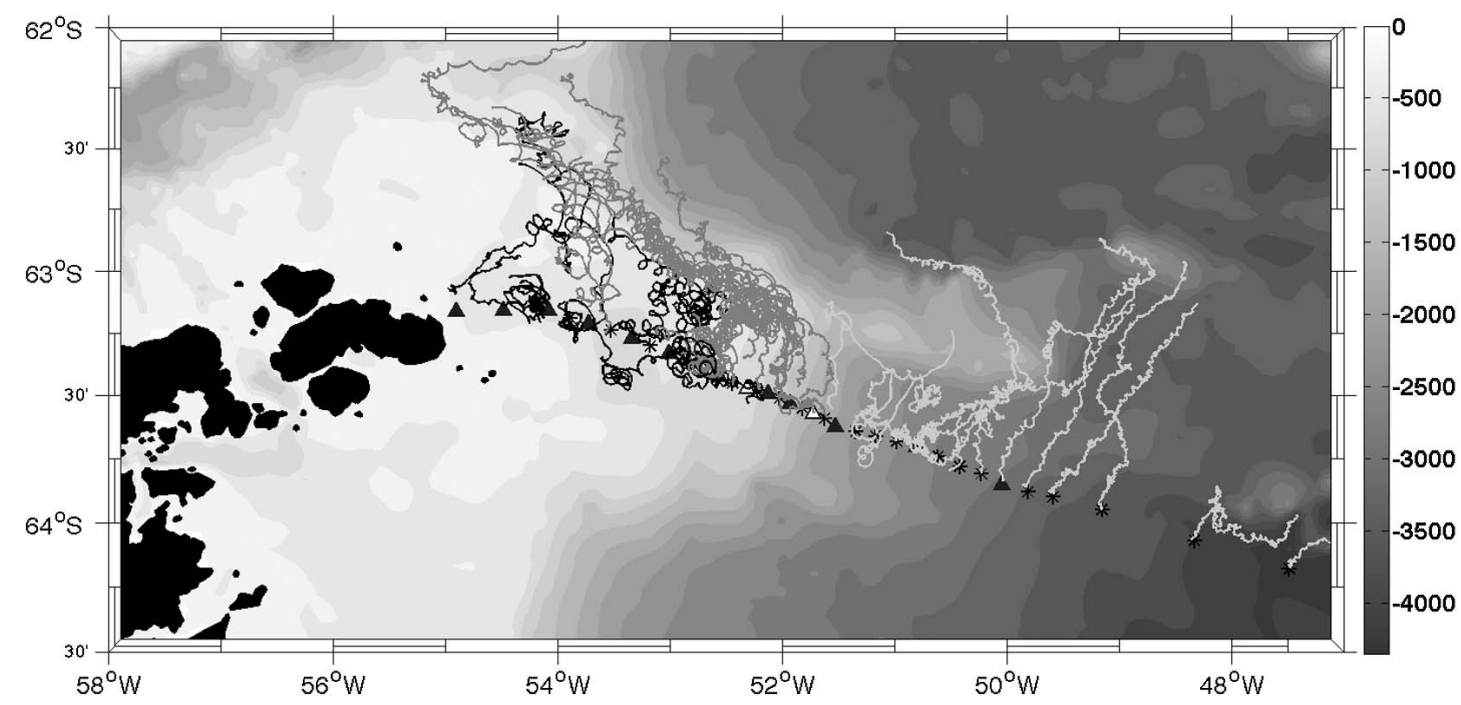

Figure 3. Initial 18 days of unfiltered trajectories of 36 Lagrangian drifters deployed during ADELIE. These are shown superimposed on the bathymetry from ETOPO2. The corkscrew behavior is evidence of the high frequency motion generated by inertial oscillations and tides. Black/mid/light gray trajectories move over continental shelf/continental slope/deep waters. Black triangles/asterisks mark SVP-G/SVP drifters. Clusters of 3 SVP-G drifters were deployed simultaneously at the two sites marked with open triangles.

anticyclonic (positive, anticlockwise) for both tidal constituents $\left(\mathrm{K}_{1}\right.$ and $\left.\mathrm{M}_{2}\right)$; only a few ellipses rotate in the opposite sense due to local interaction with topographic features.

[21] In the southern hemisphere inertial oscillations also rotate anticyclonically. The tidal ellipses (Figure 5) show that the linear superposition of tidal and inertial currents will necessarily be more significant on the shelf and continental slope than in deep waters where tidal currents are small. A current generated by a wind pulse that interacts with another periodic current can either enhance or inhibit the preexisting motion depending on whether the interaction occurs in phase or out of phase, respectively [e.g., Gill, 1982]. Furthermore, resonance is possible if both phenomena have the same frequency [e.g., Simpson et al., 2002]. Finally, nonlinear enhancement is conceivable when both flows are strong and interact in phase.

[22] Figure 6 presents the rotary power spectra for the 36 drifters. In estimating those spectra we are implicitly assuming that the flow is horizontally homogeneous in the region sampled by each drifter. The first 26 spectra correspond to shallow drifters and all exhibit similar shapes. A broad peak includes both the semidiurnal tidal frequency $\left(1 / 12.421 \mathrm{~h}^{-1}\right)$ and the inertial frequency (approximately $\left.1 / 13 \mathrm{~h}^{-1}\right)$. Another peak occurs at the diurnal tidal frequency $\left(1 / 23.934 \mathrm{~h}^{-1}\right)$. In all cases, the anticyclonic (anticlockwise; dashed black line) spectrum is the more energetic, often by one order of magnitude. This is consistent with the expected anticyclonic sense of rotation for inertial oscillations in the southern hemisphere and for tidal currents predicted by the tide model (Figure 5). In most cases both diurnal and semidiurnal peaks reach comparable power levels. The spectra estimated from drifters 28 to 40 are representative of the surface currents far from the coast over depths that vary between 1000 and $4000 \mathrm{~m}$. The most striking difference between the deep and shallow spectra is the diurnal peak. For the deep ocean drifters this peak is either absent or it is several orders of magnitude weaker than the semidiurnal component, consistent with the weakening of the barotropic tidal currents over the deep ocean, as predicted by the tidal model ellipses (Figure 5). Displacements (as estimated by the residuals, Figure 4), and consequently residual velocities, are also smaller for the deep ocean drifters. Nevertheless, semidiurnal peaks appear in almost every deep drifter record and with an energy level comparable to that found in shallower waters. This band of motion is responsible for most of the displacement in drifters 28 to 40 . Due to their similar frequency in the spectra it is difficult to distinguish tidal from inertial contributions, and we must assume that the energy in these bands comes from both sources. The tidal model however, predicts a weakening of the semidiurnal tide comparable to that of the diurnal tide. Since many semidiurnal peaks exhibit similar power levels in the spectra for the deep and the shallow drifters, it suggests an enhancement over a simple linear combination of tidal and inertial contributions. This may be due to resonance between semidiurnal tidal currents and inertial currents of nearly the same frequency. Simpson et al. [2002] report a similar process for the diurnal frequency around the critical latitude $\left(30^{\circ} \mathrm{N}\right)$, and Robertson [2005] reports enhancement of the magnitude of the semidiurnal current in a numerical model of the Weddell Sea.

[23] Summarizing, the high-frequency currents exhibit sharp differences between the deep ocean and the shallower waters of the continental slope and shelf. Displacement over deep waters are about half those over the continental shelf and slope. Clearly, models that parameterize subgrid dispersion processes would have to include this spatial pattern 


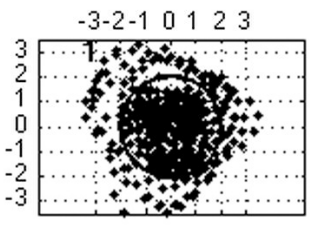

2
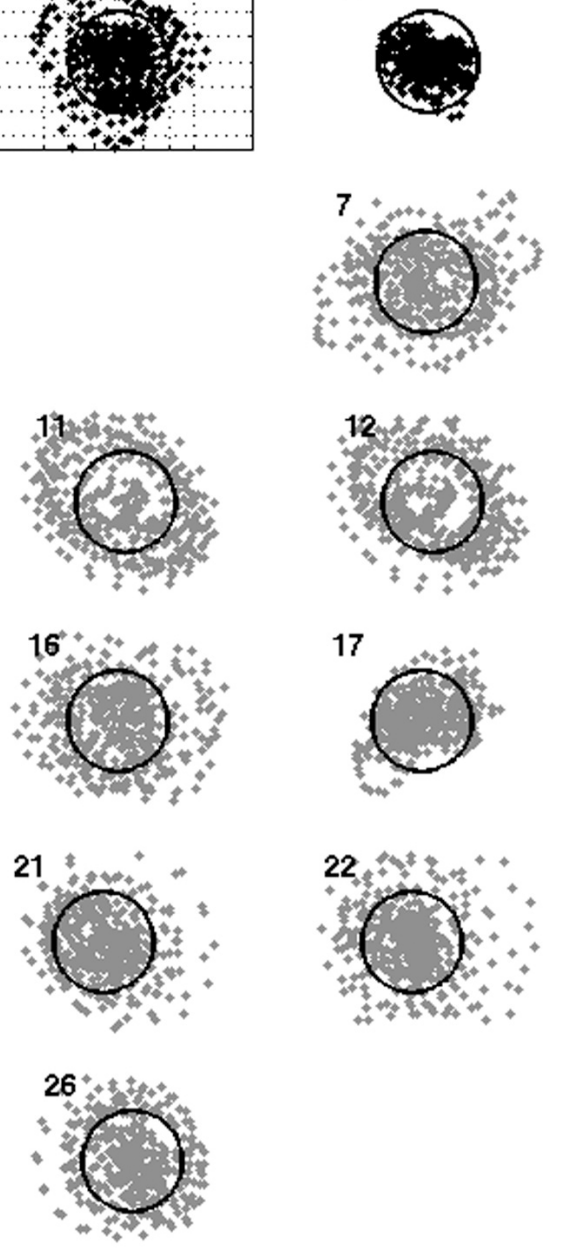

31<smiles>C1=CCCCCCCC1</smiles>
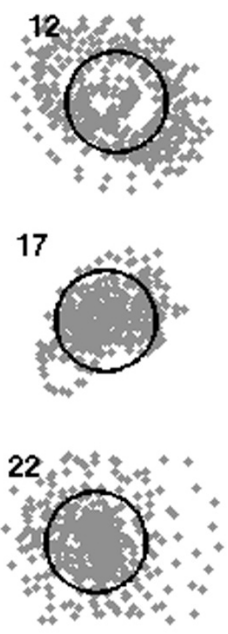

28

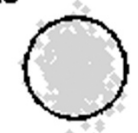

33

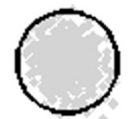

37

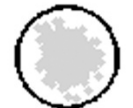

38

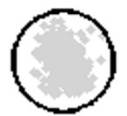

3
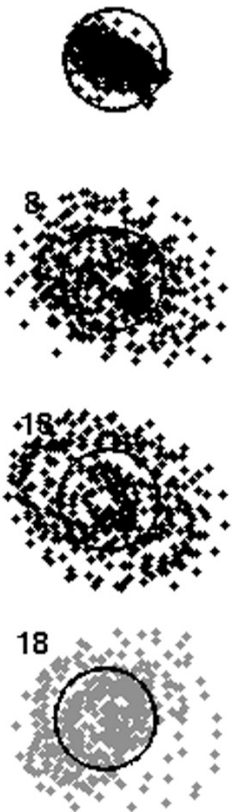
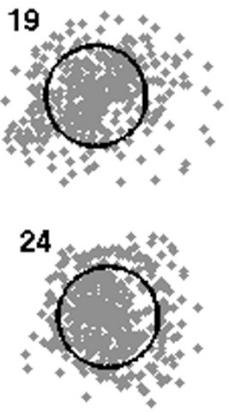

29

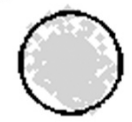

34
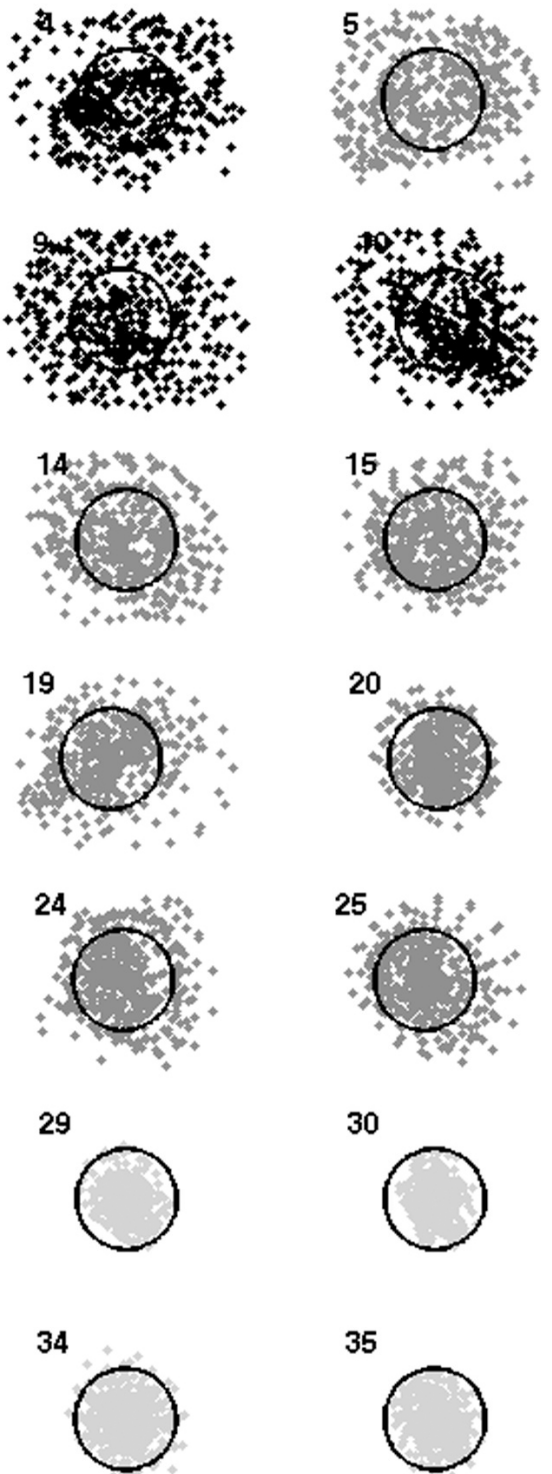

30

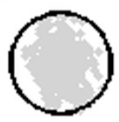

35

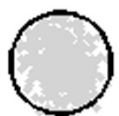

39

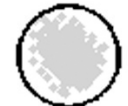

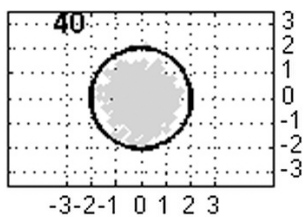

Figure 4. Residual trajectory plots for the initial 18 days of the ADELIE drifters, in sequential deployment order (as indicated in each plot). Drifters 6, 23, 27 and 32 are excluded due to their short life. Black/ mid-gray/light gray colors correspond to drifters in continental shelf/slope/deep waters, as in Figure 3 . All axes are in kilometers and a 2-km circle is drawn as reference.

to reproduce this behavior. In section 4 we propose a new parameterization scheme.

\section{Parameterization of Subgrid-Scale Motion in Particle-Tracking Modeling}

[24] Off-line drifter modeling (particle-tracking) studies have included the effects of dispersion processes on scales smaller than the grid of the underlying ocean model by including stochastic transport models of various complexity [e.g., Berloff and McWilliams, 2002]. The simplest of these stochastic models simulates small-scale motion as diffusion in the form of a random walk, which is added to the advective displacement. It has been shown that more sophisticated models tend to simulate better the statistical properties of particle trajectories influenced by turbulent motion, eddies, and tides [e.g., Berloff and McWilliams, 2002, Griffa et al., 2004, Veneziani et al., 2004]. However, the simple diffu- 

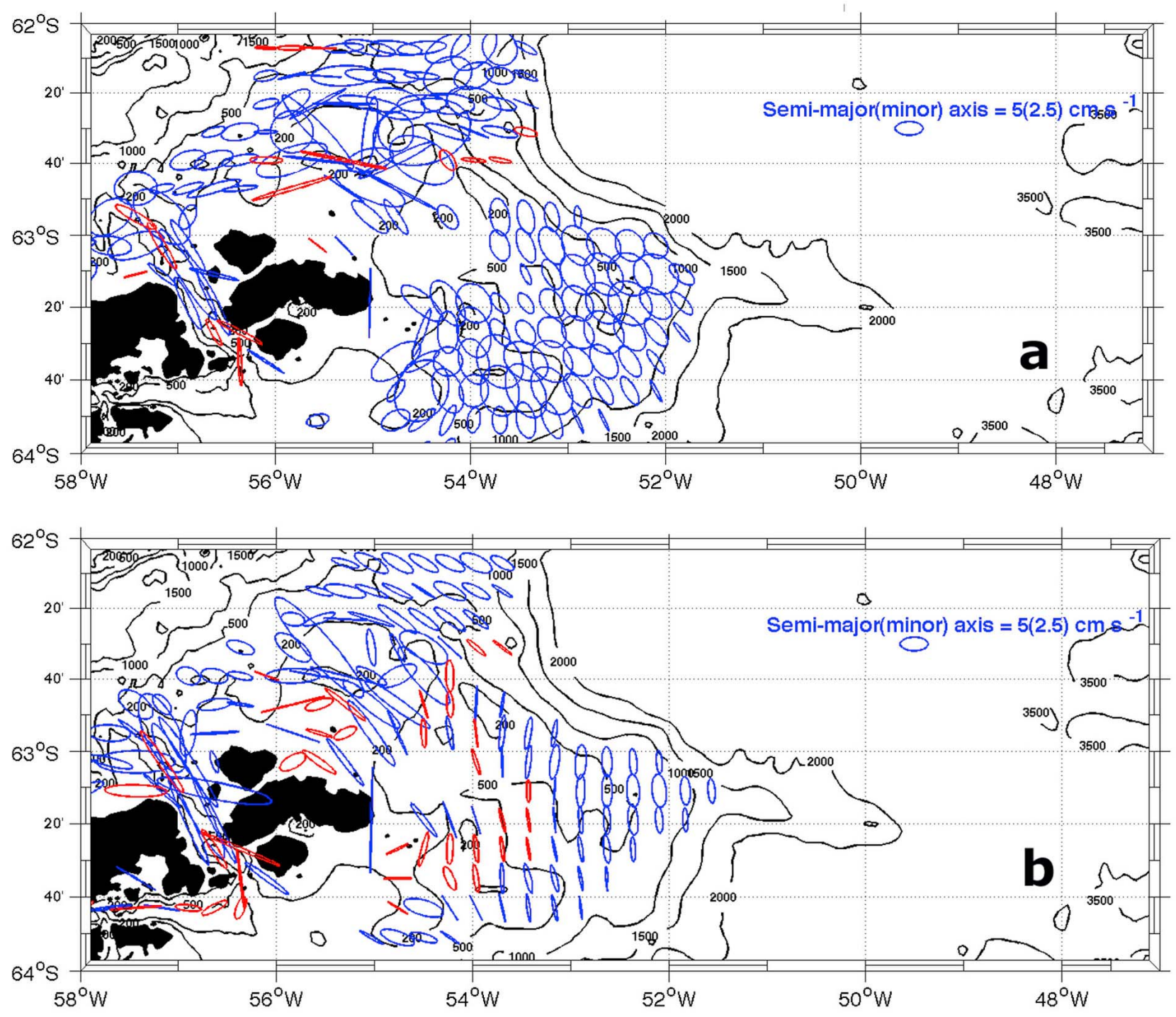

Figure 5. Tidal ellipses for (a) K1 (diurnal) and (b) M2 (semidiurnal) constituents predicted by the AntPen tide model. The semi-major axes are proportional to the magnitude extremes during one period (ellipses not drawn for semi-major axes $<5 \mathrm{~cm} \mathrm{~s}-1$, see the scale in the top right). Blue/red values indicate anticyclonic (anticlockwise)/cyclonic (clockwise) rotation.

sion model is often used for a wide range of topics including dispersion on scales beyond diffusive motion [Ribergaard et al., 2004, Thorpe et al., 2004, Sentchev and Korotenko, 2005] since it is an easy to implement and computationally cost effective method. Given the uncertainties regarding the influence of tidal and inertial motion, and the lack of knowledge of accurate wind forcing in our study region, we aim to demonstrate how a simple model can easily be tuned to provide more accurate results with only slight increases in complexity and computational cost.

[25] In the particle-tracking model used in this study, the displacement by advection is tracked using a 2-D RungeKutta scheme. To incorporate horizontal diffusion in 2-D space, a random walk is given to the particle at each time step $k$ following the method of Evans and Noye [1995]. The walk has random magnitude, $d$, and random direction, $\Theta$.
The new particle position at time step $n+1$, taking into account both advection by current velocity $(u, v)$ and diffusion, is then

$$
\begin{gathered}
x^{k+1}=x^{k}+u^{k+\frac{1}{2}} \Delta t+d \cos \Theta, \\
y^{k+1}=y^{k}+v^{k+\frac{1}{2}} \Delta t+d \sin \Theta,
\end{gathered}
$$

where

$$
d=R_{d} \sqrt{12 D_{h} \Delta t} \text { and } \Theta=2 \pi R_{\Theta},
$$

$D_{h}$ is the horizontal diffusivity and $R_{d}$ and $R_{\Theta}$ are random numbers distributed uniformly between 0 and $1 . D_{h}$ is here taken to be $100 \mathrm{~m}^{2} \mathrm{~s}^{-1}$ following Thorpe et al. [2004] and $\Delta t$ is the length of the time step (8640 s). 

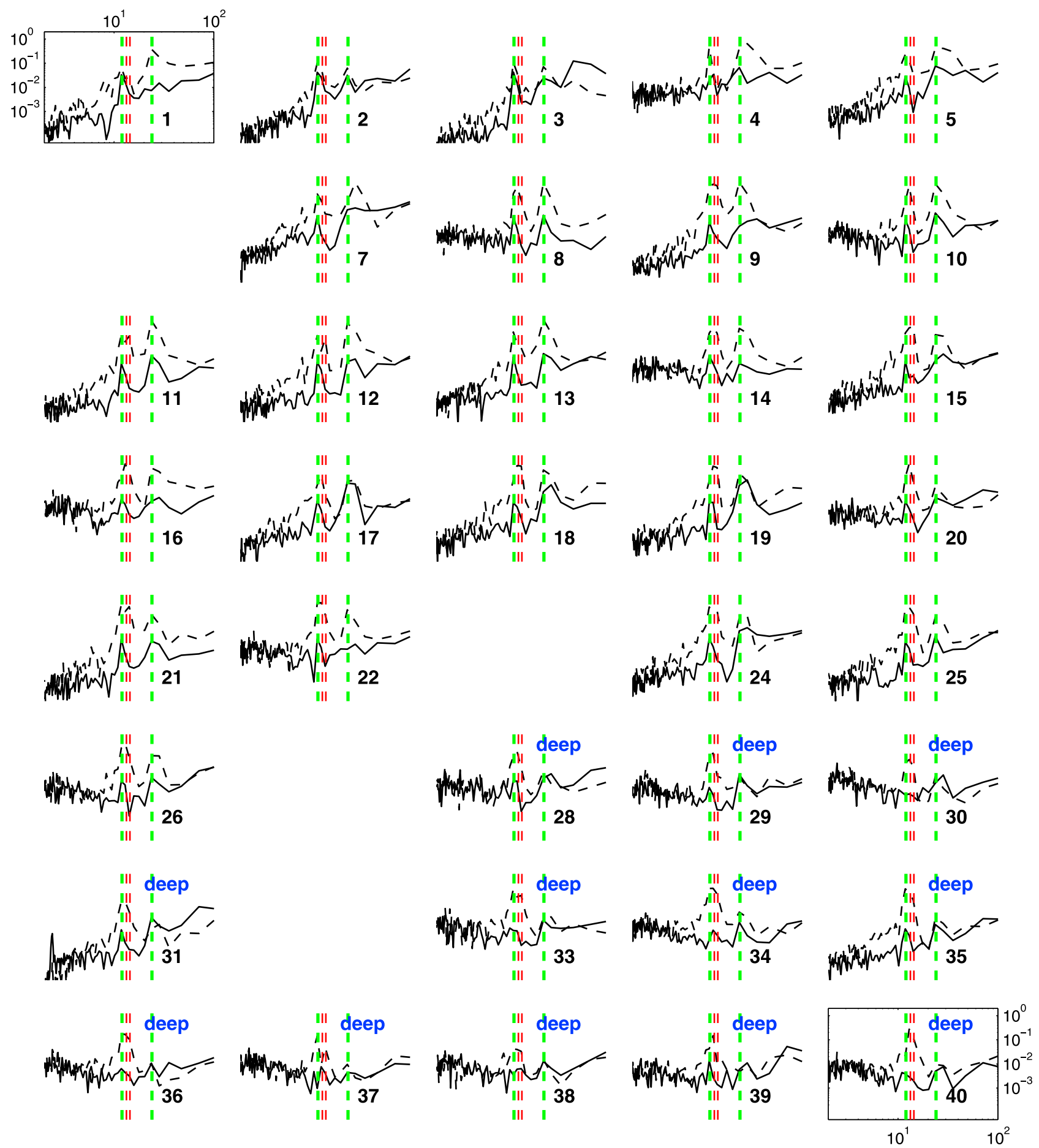

Figure 6. Rotary spectra computed from the velocity of the ADELIE drifters, in sequential deployment order (as indicated in each plot). Drifters 6,23, 27 and 32 are too short lived to estimate the spectra. The horizontal $\mathrm{x}$-axis is in hours with green vertical lines marking the diurnal and semi-diurnal tidal periods. Red vertical lines mark the inertial period within the latitude range of the data. Anticlockwise/clockwise spectral components are drawn with dashed/continuous lines. Drifters 28 to 40 are marked as deep-water drifters. 


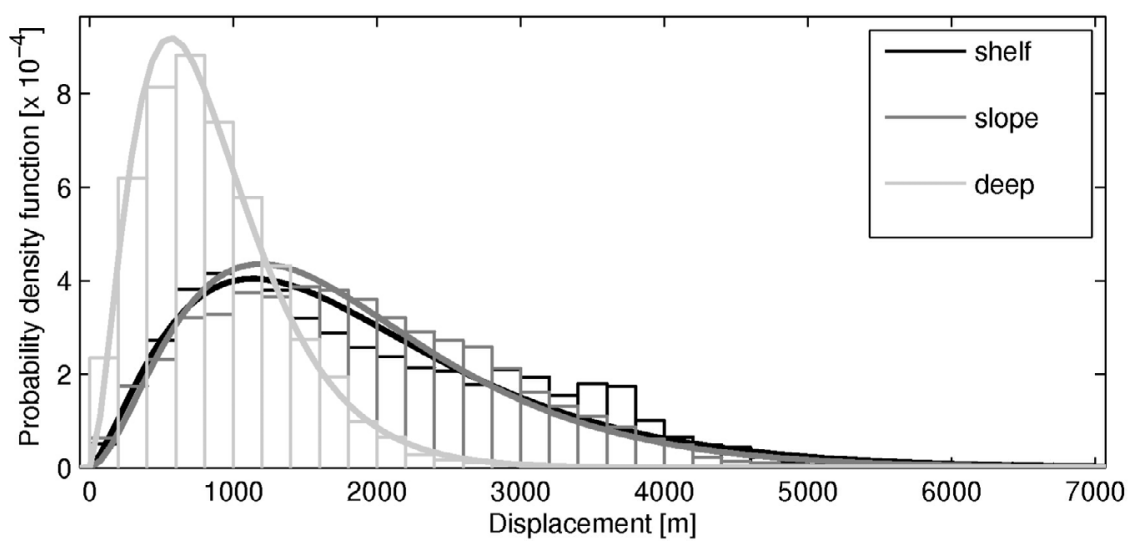

Figure 7. Histogram of displacements of the ADELIE drifters with fitted Gamma distribution curves. Hourly values of displacements from the mean drifter trajectory from all drifters apart from Drifter 32 during the 18-day period of contemporaneous data were used. The drifters were grouped into drifters on the continental shelf, slope, and in deep water as in Figure 3.

[26] The random walk scheme described thus far is an often-used scheme applied in previous studies of, for example, retention in coral reefs, larval and planktonic transport, and dispersion of water masses (Spagnol et al. [2002], Ribergaard et al. [2004], and Sentchev and Korotenko [2005], respectively). Here we investigate whether using the displacement characteristics obtained from the ADELIE drifters can improve the random walk parameterization. In this approach we apply a perturbation to the displacements from which velocities are obtained. We divide the drifters into three groups following the classification in section 3 (Figures 2 and 4): (1) continental shelf at depths $<200 \mathrm{~m}$ (drifters 1-4, 8-10, and 13), (2) continental slope ( $>200$ to $1000 \mathrm{~m}$; drifters 5-7, 11, 12, and 14-26), and (3) deep waters ( $>1000 \mathrm{~m}$; drifters 28-31 and 33-40). Displacements are derived from those shown in Figure 4 as the distance from the mean drifter trajectory at each position. Figure 7 shows the distribution of the displacements in form of probability density functions (PDF). The PDF of the displacements can be characterized by a gamma function characterized by the shape, $a$, and scale, $b$, parameters fit to each set of drifters:

$$
f(x \mid a, b)=\frac{1}{b^{a} \Gamma(a)} x^{a-1} \exp \left(\frac{x}{b}\right),
$$

where $\Gamma(\cdot)$ is the gamma function. The values for the depthdependent parameters $a$ and $b$ of the displacement distributions are given in Table 1. For the shelf PDF we used all shelf drifters in Figure 4, including drifters 2 and 3 that are later described as trapped within an eddy (see section 5). We wish to incorporate all displacements sampled on the shelf in the estimate of this PDF.

[27] Using these parameters, we derive the random displacement depending on the water depth at the drifter location by replacing $d$ in equation (7) by

$$
d=f\left(x \mid a_{\mathrm{depth}}, b_{\mathrm{depth}}\right) .
$$

[28] Since the residual trajectory of the ADELIE drifters (Figure 4) does not display directional preferences, the direction of the random displacement remains uniformly distributed. We released 500 drifters at each of the ADELIE deployment locations (see Figure 1 and Thompson et al. [2009]) on the model day corresponding to 9 February 2007 and tracked them for 18 model days, using daily velocity output from HYCOM. Sensitivity tests have shown that 500 drifters per location are sufficient to produce a uniform spread in all directions [Renner, 2010]. The length of the time step for the particle-tracking algorithm, $\Delta t$, is 8640 s, satisfying the Courant-Friedrich-Lewy stability criterion [Courant et al., 1928]. HYCOM uses hybrid coordinates in the vertical; therefore, vertical grid points vary both spatially and horizontally. For this study, the model velocities were interpolated onto a fixed depth of $15 \mathrm{~m}$ to match the drogue depth of the ADELIE drifters.

[29] Figure 8 shows the number of modeled drifters passing through each grid box of a $1 / 10^{\circ}$ grid, normalized by the total number of drifters released, both for the simulations using the uniformly distributed random walk scheme (Figure 8, top) and the gamma-distributed random walk (Figure 8, middle). The difference in the normalized numbers of drifters passing through a grid box between the runs with the two different schemes is presented in Figure 8 (bottom). Positive(negative) values (red(blue)) indicate that more (fewer) drifters advected with gamma-distributed random walk displacements are found in a given grid box than with the uniformly distributed displacements. The modeled drifters were tracked for the model period that corresponds to the dates of the ADELIE drifters in February 2007.

[30] In general, both simulations with the different random walk schemes capture the general pattern of the ADELIE drifters. Those in the shelf group (released at the deployment positions of ADELIE drifters 1, 2, 3, 4, 8, 9, 10, and 13) move toward the entrance of Bransfield Strait, and the entrapment of the ADELIE drifters 3 and 4 in an eddy is

Table 1. Parameters of the Best Fit Gamma Distribution for the

\begin{tabular}{|c|c|c|c|}
\hline Parameter & $\begin{array}{c}\text { Shelf } \\
\text { (0-200 m depth) }\end{array}$ & $\begin{array}{c}\text { Slope } \\
\text { (200-1000 m depth) }\end{array}$ & $\begin{array}{c}\text { Deep } \\
(>1000 \mathrm{~m} \text { depth })\end{array}$ \\
\hline$a_{\text {depth }}$ (shape) & 2.48 & 2.86 & 2.85 \\
\hline$b_{\text {depth }}$ (scale) & 766 & 642 & 305 \\
\hline
\end{tabular}
Three Drifter Groups in Figure 3 


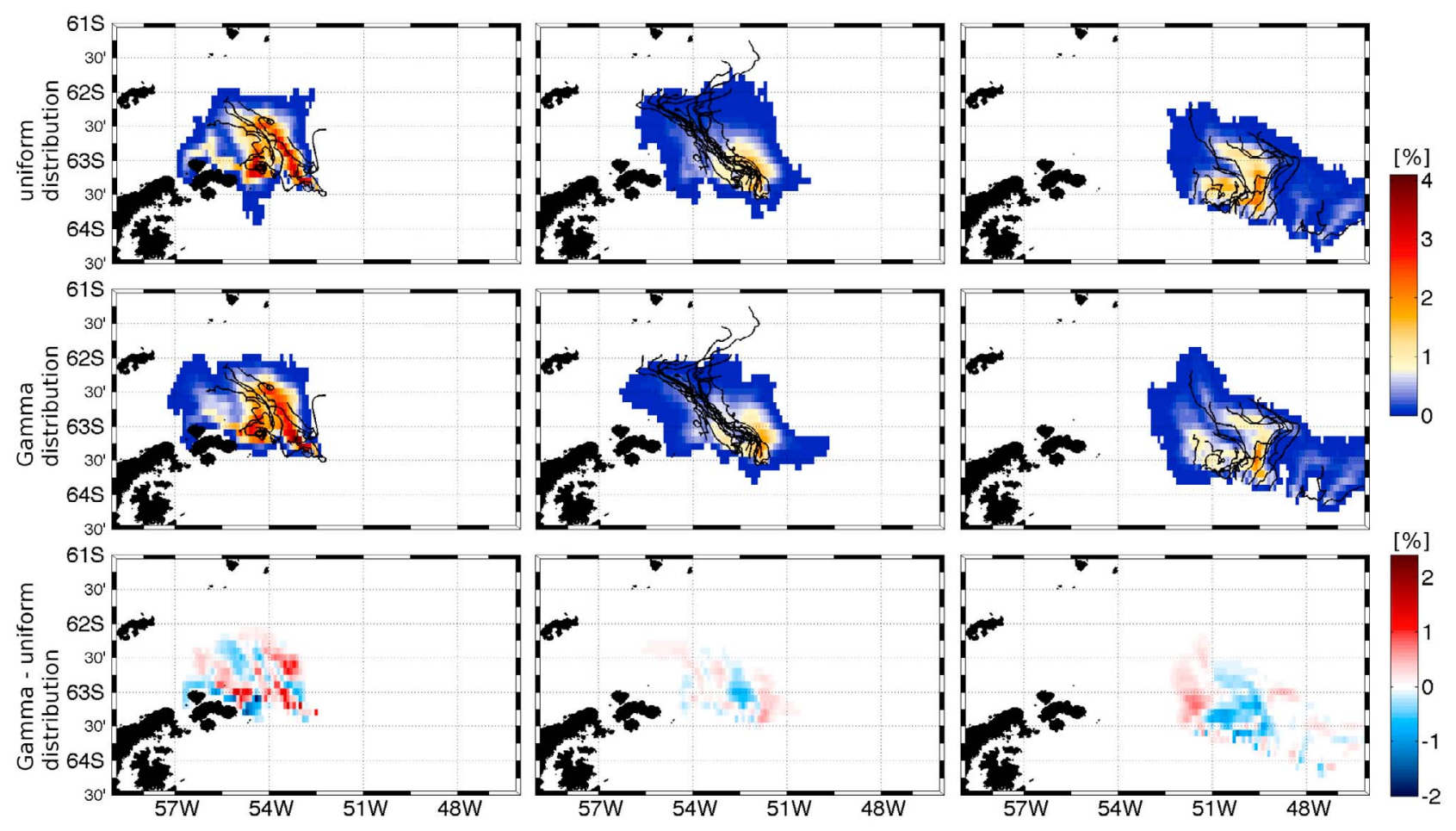

Figure 8. Maps of relative numbers of modeled drifters passing through a grid box of a $1 / 10^{\circ}$ grid (top) using uniformly distributed random displacements, (middle) using Gamma distributed random displacements, and (bottom) the difference. The maps are calculated separately for model drifters deployed at (left) the start positions of ADELIE drifters above the continental shelf, (middle) the slope and (right) the deep water and run for 18 days. Overlain are the mean ADELIE drifter trajectories of the drifters in the respective groups for the first 18 days of drift (black lines).

also represented in the model simulations. The slope group (deployed at start positions of ADELIE drifters 5, 6, 7, 11, 12, 14-26) moves northwestward in a wide band. The drifters released above deep water (start positions of ADELIE drifters 27-31 and 33-40) are less clustered than those in the other groups and move northward along the topography. There are some differences between the simulations. On the shelf, the drifters experiencing the gammadistributed displacements (in the following referred to as "gamma drifters") correct the southward movement of some drifters in the simulation with the uniformly distributed random walk ("uniform drifters"). The gamma drifters move further west than the uniform drifters, which corresponds better to the general travel direction of the ADELIE drifters above the shelf. Both the average of the gamma-distributed displacements and the uniform distributed displacements on the shelf are too small compared with the ADELIE drifter displacements (Table 2). The variance of the gamma dis- placements is closer to the observations than the uniform displacements. The same applies to the mean and the variance of the displacements above the continental slope. The gamma displacements influence the pattern of the drifter spreading on the slope in a similar way to the pattern on the shelf: The modeled drifters follow a path that is aligned more closely with the paths of the ADELIE drifters and extends northwestward.

[31] The directional differences on the shelf and especially on the slope are likely a result of the, on average, smaller displacements by the gamma distribution (Table 2). These differences increase from the shelf toward the deep Weddell Sea and allow the advective motion to dominate the trajectories in regions with fast currents as, for example, in the jet associated with the Antarctic Slope Front. The largest difference between the gamma and uniform drifters is visible in the deep drifter group. The mean of the uniform displacements is now overestimating the observed mean,

Table 2. Mean and Variance of Mesoscale Displacements of the ADELIE Drifters and of the Displacements by the Two Random Walk Schemes for the Modeled Drifters ${ }^{\mathrm{a}}$

\begin{tabular}{|c|c|c|c|c|c|c|c|c|c|}
\hline & \multicolumn{3}{|c|}{ Shelf } & \multicolumn{3}{|c|}{ Slope } & \multicolumn{3}{|c|}{ Deep } \\
\hline & ADELIE & Uniform & Gamma & ADELIE & Uniform & Gamma & ADELIE & Uniform & Gamma \\
\hline $\operatorname{Mean}\left(\times 10^{3} \mathrm{~m}\right)$ & 1.90 & 1.61 & 1.56 & 1.83 & 1.61 & 1.48 & 0.87 & 1.61 & 0.99 \\
\hline Variance $\left(\times 10^{6} \mathrm{~m}^{2}\right)$ & 1.28 & 0.86 & 1.11 & 0.96 & 0.86 & 1.06 & 0.24 & 0.86 & 0.49 \\
\hline
\end{tabular}

${ }^{\mathrm{a}}$ Drifters are divided into three groups (shelf, slope, and deep) as in Figure 3. 

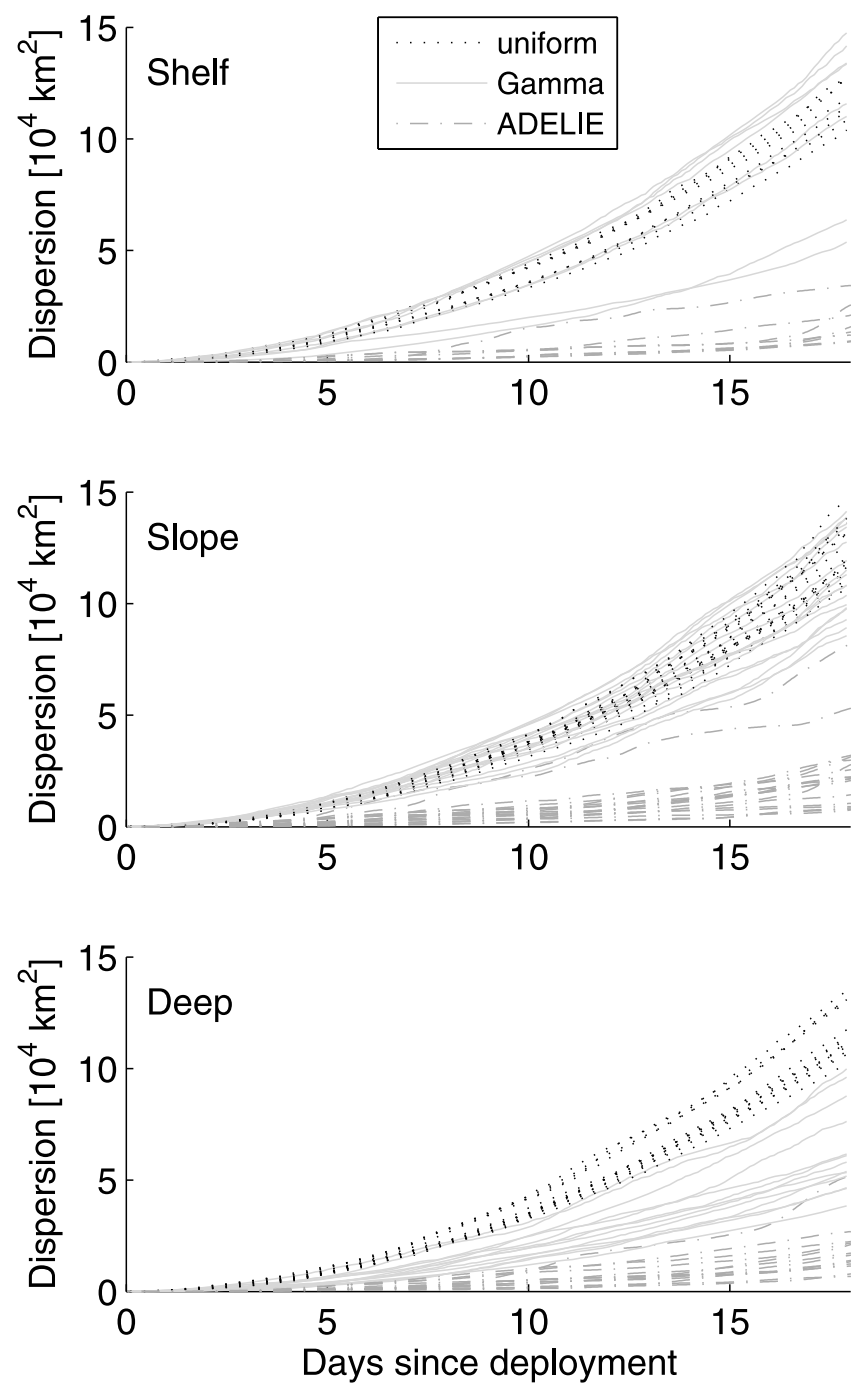

Figure 9. Dispersion of modeled and ADELIE drifters during the first 18 days after deployment.

and the gamma displacements are more realistic. The variance is overestimated by both schemes; however, the gamma distribution is closer to the observations. The uniform drifters occupy mainly two clear regions. These also appear in the gamma drifters, but here, the regions match more closely the ADELIE drifters and capture the ADELIE drifter paths that follow the rim of the Powell Basin [Thompson et al., 2009]. The spread of the modeled drifters also agrees well with the distances covered by the ADELIE drifters during the 18 days after deployment.

[32] Dispersions calculated as the mean square displacement from the initial position are used as a comparison (Figure 9). In the case of the modeled drifters, this is the average of over 500 drifters deployed in the same location at each time step. Both the uniform and the gamma drifters show too large dispersions, particularly over the shelf. On the slope, the gamma distribution leads to slightly closer values to the observations than the uniform distribution. The biggest improvement is visible in the drifter group moving over the deeper Weddell Sea where dispersions of the gamma drifters are almost half of the values for the uniform drifters, but still overestimating the observed dispersion by a factor of 3. The gamma drifters are still far from a perfect match, but they are an improvement to the random walk scheme particularly on deep water.

\section{Discussion}

[33] The corkscrew paths superimposed on the mean Lagrangian tracks of surface drifters are persistent, highfrequency spectral features of the surface currents around the Antarctic Peninsula. They result mainly from a combination of tidal and inertial currents, and nonlinear interactions between these processes are possible during intense wind forcing events. Examination of the Lagrangian residual displacements shows large differences between shelf, slope, and deepwater environments. The depth of the water column is important due to the stronger influence of tidal and inertial currents over the continental shelf and slope, compared with the weaker tidal currents found in deeper waters of the Weddell Sea. The change in relative importance of these processes is supported by variations in the rotary spectra in the different regions. The magnitude of the residual displacements is decoupled from the variability of the mean flow. For instance, the presence of the Antarctic Slope frontal jet has no apparent effect on the residual displacements.

[34] Although tidal currents are weak over deep isobaths, power in the semidiurnal band remains significant. Its spectral peak is nearly the same magnitude as that in shallow waters. This is thought to be due to resonance with inertial currents and/or to nonlinear enhancement when both flows are strong and interact in phase. Enhancement of the semidiurnal frequency away from the continental shelf may also be related to spatial variability in the strength of wind forcing.

[35] The observed high-frequency variability is not completely explained by tides and inertial oscillations alone. In the high latitudes of the Weddell Sea the conditions exist for the generation of very small (diameter of the order of the internal Rossby radius) mesoscale surface eddies. Several phenomena may be responsible for the presence of eddies. Taylor columns and eddies can be formed when a current interacts with a seamount [see, e.g., Roden and Taft, 1985]. Also, from the Rossby adjustment problem [Gill, 1982], geostrophic balance is expected to occur for typical lengths of the order of the Rossby radius and lasting more than the inertial period. A perturbation of the pressure gradient will attain geostrophic balance if it lasts more than, in this region, $13 \mathrm{~h}$ and spans a length scale of 5 to $10 \mathrm{~km}$. If the ensuing motion contains vertical shear it is likely to generate geostrophic - mesoscale - eddies by the mechanism of baroclinic instability [Pedlosky, 1998].

[36] Any wind pulse lasting more than half a day and blowing over several tens of kilometers will create a surfaceintensified perturbation capable of developing into a small geostrophic, surface-intensified (baroclinic) eddy. Baroclinic eddies do not have a sign preference, both cyclonic and anticyclonic ones are likely to be present in these observations superimposed onto the transient inertial oscillations and the barotropic tidal currents. We briefly mentioned in section 3 that the anomalous residual trajectories of drifters 2 and 3 (in Figure 4) are attributed to an eddy. Figure 10 contains the initial 18 days of data from those drifters 


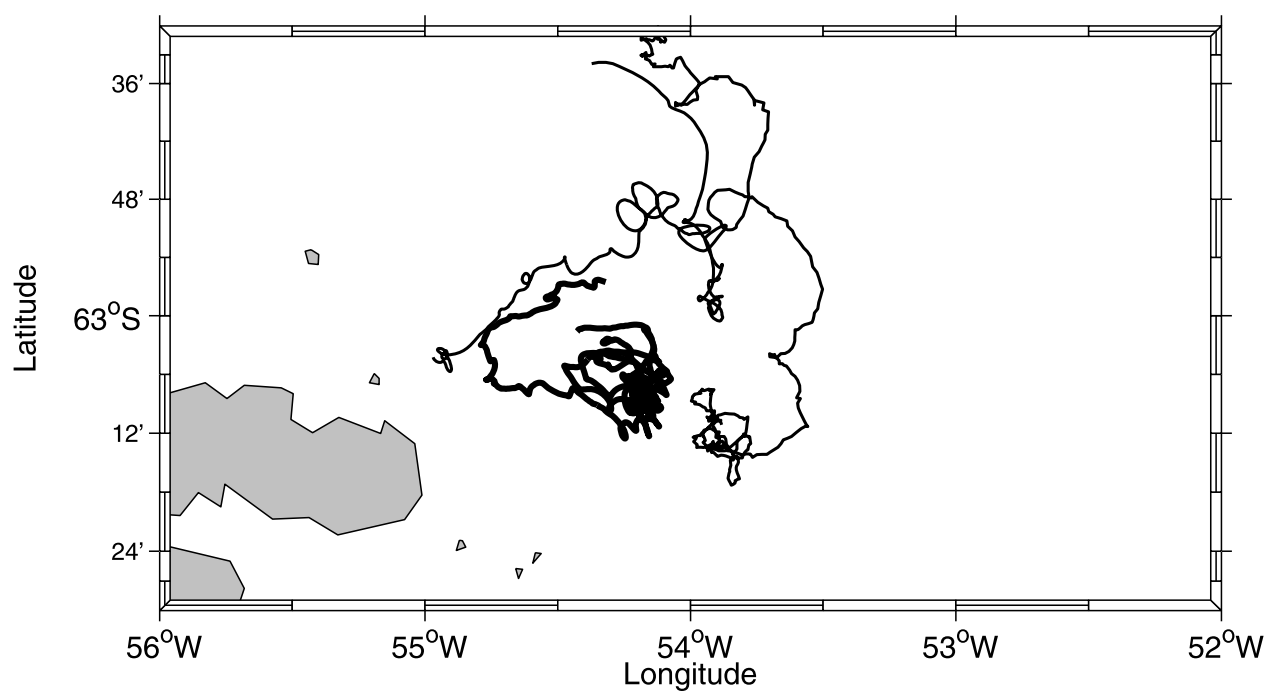

Figure 10. Tracks of 18 days of data for 4 drifters deployed during ADELIE. Drifters 2 and 3 (thick lines) remain trapped within an eddy.

while trapped within this feature. Clearly, eddies can influence horizontal diffusivities, but our data set does not allow for a better description. A more detailed study, perhaps focused on the effect of wind events, would be useful to advance the knowledge on the role that these eddies play in the physics of dispersion at high latitudes.

[37] The gamma scheme tested here provides a parameterization of mesoscale horizontal displacements that varies in space according to the region being modeled, with larger displacements on the shelf and continental slope and smaller displacements in deep water. The simulation of drifters with the new parameterization in an off-line drifter-tracking algorithm provides more realistic drifter distributions that simulate well the observed drifter paths and their steering by topography. The improvement is gained by including lateral changes in the dispersion of the residual trajectories, as supported by the drifter trajectories. This results in a more realistic subgrid-scale dispersion scheme than the uniform random walk scheme. This is vital for modeling studies that, inevitably, are restricted by model resolution. It also highlights the need to improve the parameterizations of dispersion used in models to improve our understanding of Lagrangian particle transport in coastal regions where many complex phenomena such as tides, eddies, and inertial oscillations interact. The spatial variability of the high-frequency motions may be decoupled from the spatial variability in dispersion by the mean flow. Capturing both processes is required for accurate simulations of particle dispersion.

[38] Acknowledgments. This paper is dedicated to the memory of Peter Niiler, who generously provided drifters for this project, and also in recognition of his many contributions. We thank the officers, scientists and crew of the RRS James Clark Ross, cruise JR158, for contributing to the success of the ADELIE project. We also wish to acknowledge the work of three anonymous reviewers. We thank the Royal Society for funding (grant 2006/R2) this International Joint Project between Mexico and the United Kingdom, the NERC Antarctic Funding Initiative for funding the ADELIE project (grant NE/C50633X/1), the Oceanology Division of CICESE and CICESE Unidad La Paz. A.T. is a SNI grant holder. A.H.H.R was funded by EU Marie Curie Early Stage Training Fellowship in Antarctic Air-Sea-Ice Science by the European Commission Marie Curie Actions at the School of Environmental Sciences, University of East Anglia and the
British Antarctic Survey (contract MEST-CT-2004-514159). A.F.T. was supported by a NERC grant (NE/E013171/1). We used the Tide Model Driver Matlab toolbox from Earth \& Space Research (ESR; http://www. esr.org/ptm index.html). HYCOM simulations were performed as part of the Office of Naval Research project Eddy Resolving Global Ocean Prediction Including Tides using challenge and nonchallenge times from the U.S. Department of Defense High Performance Computing Modernization Office on Cray XT5 and IBM P6 computers at the Navy DOD Supercomputing Resource Center, Stennis Space Center.

\section{References}

Beardsley, R. C., R. Limburner, and L. Rosenfeld (1985), Introduction: CODE-2 moored array and large scale data report, Tech. Rep. WHOI 85-35, 234 pp., Woods Hole Oceanographic Inst., Woods Hole, Mass. Beckmann, A., H. H. Hellmer, and R. Timmermann (1999), A numerical model of the Weddell Sea: Large-scale circulation and water mass distribution, J. Geophys. Res., 104(C10), 23,375-23,391, doi:10.1029/ 1999JC900194.

Berloff, P. S., and J. C. McWilliams (2002), Material transport in oceanic gyres. Part II: Hierarchy of stochastic models, J. Phys. Oceanogr., 32(3), 797-830, doi:10.1175/1520-0485(2002)032<0797:MTIOGP>2.0.CO;2.

Bleck, R. (2002), An oceanic general circulation model framed in hybrid isopycnic-Cartesian coordinates, Ocean Modell., 4, 55-88, doi:10.1016/S1463-5003(01)00012-9.

Courant, R., K. Friedrichs, and H. Lewy (1928), Über die partiellen differenzengleichungen der mathematischen physik, Math. Ann., 100(1), 32-74, doi:10.1007/BF01448839.

Davis, R. E. (1991), Observing the general circulation with floats, Deep Sea Res., Part I, 38, S531-S571.

Emery, W. J., and R. E. Thompson (2004), Data Analysis Methods in Physical Oceanography, Elsevier, New York.

Evans, P. L., and B. J. Noye (1995), A model for fast oil spill trajectory prediction in shallow gulfs, in Recent Advances in Marine Science and Technology, edited by O. Bellwood, H. Choat, and N. Saxena, pp. 119-130, PACON Intl., Townsville, Queensl., Australia.

Fahrbach, E., and A. Beckmann (2001), Weddell Sea circulation, in Encyclopedia of Ocean Sciences, vol. 6, edited by S. A. Thorpe and K. K. Turekian, pp. 3201-3209, Academic, San Diego, Calif., doi:10.1006/ rwos.2001.0371.

Fitzwater, S. E., K. S. Johnson, R. M. Gordon, K. H. Coale, and W. O. Smith (2000), Trace metal concentrations in the Ross Sea and their relationship with nutrients and phytoplankton growth, Deep Sea Res., Part II, 47, 3159-3179, doi:10.1016/S0967-0645(00)00063-1.

Gill, A. (1982), Atmosphere-Ocean Dynamics, Academic, San Diego, Calif.

Griffa, A., L. I. Piterbarg, and T. Özgökmen (2004), Predictability of Lagrangian particle trajectories: Effects of smoothing of the underlying Eulerian flow, J. Mar. Res., 62(1), 1-35, doi:10.1357/00222400460744609. 
Hansen, D. V., and P. M. Poulain (1996), Quality control and interpolations of WOCE-TOGA drifter data, J. Atmos. Oceanic Technol., 13, 900-909, doi:10.1175/1520-0426(1996)013<0900:QCAIOW>2.0.CO;2.

Johnson, J. (2011), Deep Ocean Exchange with the Shelf (DOES), Ocean Sci., 7, 101-109.

Marr, J. (1962), The natural history and geography of the Antarctic krill (Euphausia superba Dana), in Discovery Reports, vol. 32, pp. 33-464, Cambridge Univ. Press, Cambridge, U. K.

Martin, J. H., R. M. Gordon, and S. E. Fitzwater (1990), Iron in Antarctic waters, Nature, 345, 156-158, doi:10.1038/345156a0.

Murphy, E. J., et al. (2007), Spatial and temporal operation of the Scotia Sea ecosystem: A review of large-scale links in a krill centred food web, Philos. Trans. R. Soc. B, 362, 113-148, doi:10.1098/rstb. 2006.1957.

Padman, L., H. A. Fricker, R. Coleman, S. Howard, and S. Erofeeva (2002), A new tidal model for the Antarctic ice shelves and seas, Ann. Glaciol., 34, 247-254, doi:10.3189/172756402781817752.

Pedlosky, J. (1998), Ocean Circulation Theory, Springer, New York.

Renner, A. H. H. (2010), Advection and dispersion of modeled drifters in the Weddell and Scotia Seas, Ph.D. thesis, 173 pp., School of Environ. Sci., Univ. of East Anglia, Norwich, U. K.

Ribergaard, M. H., S. A. Pedersen, B. Ådlansvik, and N. Kliem (2004), Modelling the ocean circulation on the West Greenland shelf with special emphasis on northern shrimp recruitment, Cont. Shelf Res., 24, 1505-1519, doi:10.1016/j.csr.2004.05.011.

Robertson, R. (2005), Baroclinic and barotropic tides in the Weddell Sea, Antarct. Sci., 17(3), 461-474, doi:10.1017/S0954102005002890.

Roden, G. I., and B. A. Taft (1985), Effect of Emperor Seamounts on the mesoscale thermohaline structure during the summer of 1982, J. Geophys. Res., 90(C1), 839-855, doi:10.1029/JC090iC01p00839.

Rosmond, T. E., J. Teixeira, M. Peng, T. F. Hogan, and R. Pauley (2002), Navy Operational Global Atmospheric Predictions System (NOGAPS): Forcing for ocean models, Oceanography, 15(1), 99-108.

Sentchev, A., and K. Korotenko (2005), Dispersion processes and transport pattern in the ROFI system of the eastern English Channel derived from a particle-tracking model, Cont. Shelf Res., 25, 2294-2308, doi:10.1016/j. csr.2005.09.003.

Simpson, J. H., P. Hyder, T. P. Rippeth, and I. M. Lucas (2002), Forced oscillations near the critical latitude for diurnal-inertial resonance,
J. Phys. Oceanogr., 32, 177-187, doi:10.1175/1520-0485(2002) $032<0177$ :FONTCL $>2.0$. CO 2 .

Spagnol, S., E. Wolanski, E. Deleersnijder, R. Brinkman, F. McAllister, B. Cushman-Roisin, and E. Hanert (2002), An error frequently made in the evaluation of advective transport in two-dimensional Lagrangian models of advection-diffusion in coral reef waters, Mar. Ecol. Prog. Ser., 235, 299-302, doi:10.3354/meps235299.

Thompson, A. F., and K. J. Heywood (2008), Frontal structure and transport in the northwestern Weddell Sea, Deep Sea Res., Part I, 55, 1229-1251, doi:10.1016/j.dsr.2008.06.001.

Thompson, A. F., K. J. Heywood, S. E. Thorpe, A. Renner, and A. Trasviña (2009), Surface circulation at the tip of the Antarctic Peninsula from drifters, J. Phys. Oceanogr., 39, 3-26, doi:10.1175/2008JPO3995.1.

Thorpe, S. E., K. J. Heywood, D. P. Stevens, and M. A. Brandon (2004), Tracking passive drifters in a high resolution ocean model: Implications for interannual variability of larval krill transport to South Georgia, Deep Sea Res., Part I, 51, 909-920, doi:10.1016/j.dsr.2004.02.008.

Veneziani, M., A. Griffa, A. M. Reynolds, and A. J. Mariano (2004), Oceanic turbulence and stochastic models from subsurface Lagrangian data for the Northwest Atlantic Ocean, J. Phys. Oceanogr., 34, 1884-1906, doi:10.1175/1520-0485(2004)034<1884:OTASMF>2.0.CO;2.

K. J. Heywood, School of Environmental Sciences, University of East Anglia, Norwich, NR4 7TJ, UK.

A. H. H. Renner, Norwegian Polar Institute, Fram Centre, N-9296 Tromsø, Norway.

A. F. Thompson, Division of Geological and Planetary Sciences, California Institute of Technology, 1200 E. California Blvd., Pasadena, CA 91125-2300, USA.

S. E. Thorpe, British Antarctic Survey, Natural Environment Research Council, High Cross, Madingley Road, Cambridge, CB3 0ET UK.

A. Trasviña, Departamento de Oceanografía Física-Unidad La Paz, Centro de Investigación Cientifica y de Educación Superior de Ensenada, Miraflores 334 e/Mulegé y La Paz, Fraccionamiento Bella Vista, La Paz 23050, Baja California Sur, México. (trasvi@cicese.mx)

L. Zamudio, Center for Ocean and Atmospheric Prediction Studies, Florida State University, Tallahassee, FL 32306-2840, USA. 